\title{
La ascensión a la montaña y la rememoración de la historia. Interpretaciones de Sierra Nevada en el montañismo del siglo XIX
}

\author{
Carlos Cornejo Nieto \\ Investigador independiente \\ soy.carlos@yahoo.es
}

Recibido: noviembre de 2015

Aceptado: julio de 2016

\section{Resumen}

Generalmente, la geografía cultural ha planteado la relación entre la memoria y el espacio geográfico como parte de los discursos de la identidad nacional, obviando otras particularidades subjetivas suscitadas por el contacto físico con la materialidad del paisaje. Centrándose en las especificidades topográficas de Sierra Nevada, este artículo reconsidera la espacialidad de la memoria como un proceso multisensorial, en el que, a través del acto físico, dinámico y geográficamente situado de la ascensión a la cumbre, se vehicula una rememoración personal del pasado. Tomando el concepto de Nora de «lugar de memoria» y las nociones fenomenológicas y ontológicas del pasado de Ingold y Deleuze, y considerando asimismo los particularismos geográficos e históricos del macizo, el artículo explora la rememoración de la historia islámica por parte de tres viajeros del siglo XIX durante su ascensión al Veleta y al Mulhacén, interpretando ambas cumbres como puntos de unión donde convergen el pasado oriental islámico y el presente occidental europeo.

Palabras clave: Sierra Nevada; montañismo; paisaje; memoria; historia islámica

Resum. L'ascensió a la muntanya i la rememoració de la història: Interpretacions de Sierra Nevada en el muntanyisme del segle XIX

Generalment, la geografia cultural ha plantejat la relació entre la memòria i l'espai geogràfic com a part dels discursos d'identitat nacional, obviant altres particularitats subjectives suscitades pel contacte físic de la materialitat del paisatge. Tot centrant-se en les especificitats topogràfiques de Sierra Nevada, aquest article reconsidera l'espacialitat de la memòria com un procés multisensorial, en el qual, a través del contacte físic, dinàmic i geogràficament situat de l'ascensió al cim, es vehicula una rememoració personal del passat. Partint del concepte de Nora de «lloc de memòria» i de les nocions fenomenològiques i ontològiques del passat d'Ingold i Deleuze, i considerant, així mateix, els particularismes geogràfics i històrics del massís, l'article explora la rememoració de la història islàmica de tres viatgers del segle xIx durant la seva ascensió al Veleta i al Mulhacén, interpretant tots dos cims com a punts d'unió on convergeixen el passat oriental islàmic i el present occidental europeu.

Paraules clau: Sierra Nevada; muntanyisme; paisatge; memòria; història islàmica 
Résumé. L'ascension en montagne et la remémoration de l'histoire: Interprétations de la Sierra Nevada dans l'alpinisme du XIXe siècle

La géographie culturelle a contemplé de manière générale la relation entre la mémoire et l'espace géographique dans le cadre des discours d'identité nationale, en ignorant d'autres particularités subjectives générées par le contact physique avec la matérialité du paysage. Se concentrant sur les spécificités topographiques de la Sierra Nevada, cet article revient sur la spatialité de la mémoire en tant que processus multi-sensoriel, où l'on véhicule une remémoration personnelle du passé à travers l'acte physique, dynamique et géographiquement situé de l'ascension vers le sommet. En considérant la notion de "lieu de mémoire " de Nora et les notions phénoménologiques et ontologiques du passé d'Ingold et de Deleuze, ainsi que les particularités géographiques et historiques du massif, l'article explore la remémoration de l'histoire islamique faite par trois voyageurs du xIxe siècle lors de leur ascension au Veleta et au Mulhacen, en interprétant les deux sommets comme points de jonction, où le passé oriental islamique et le présent occidental européen convergent.

Mots-clés: Sierra Nevada; alpinisme; paysage; mémoire; histoire islamique

Abstract. Climbing summits and remembering history: Visions of the Sierra Nevada in 19thcentury mountaineering

The cultural geography has often discussed the connection between memory and geographical space as part of the narratives on national identity, overlooking other subjective features arising from the physical contact with the materiality of landscape. By focusing on the topographical specificities of the Sierra Nevada, this article reconsiders the spatiality of memory as a multisensory process in which, through the physical, dynamic and sitelocated act of climbing to the summit, the remembrance of the past is conveyed. Drawing on Nora's concept of "place of memory" and on Ingold's and Deleuze's phenomenological and ontological notions of the past, as well as considering the geographical and historical specificities of the Betic Massif, the article explores the remembrance of Islamic history by three nineteenth-century travellers who climbed the Veleta and the Mulhacén peaks, envisioning both summits as sites where the Islamic past and the European present converge.

Keywords: Sierra Nevada; mountaineering; landscape; memory; Islamic history

\section{Sumario}

1. Introducción: la montaña y el montañismo en las humanidades

2. El primer montañismo en Sierra Nevada

3. La espacialidad de la rememoración: geografía, paisaje y memoria
4. El Veleta y el Mulhacén: lugares topográficos para la rememoración histórica

5. Conclusiones

Referencias bibliográficas 


\section{Introducción: la montaña y el montañismo en las humanidades}

Es un hecho que los sistemas montañosos siempre han suscitado un fuerte poder de atracción en el seno de las ciencias, la filosofía y la cultura de distintas civilizaciones, encarnando "procesos superpuestos de significación (como objetos sagrados, míticos, geopolíticos, naturalistas)» (Della Dora, 2011: 6). La montaña, entendida como un concepto cultural complejo de carácter histórico, constituye, en palabras de Robert MacFarlane (2003: 33), un «producto de la colaboración entre la forma física del mundo y la imaginación humana», una imbricación entre lo material y lo inmaterial.

El estudio de los significados de las montañas viene ocupando recientemente un lugar muy significativo en las humanidades y en las ciencias sociales. Las grandes cordilleras europeas, como los Alpes y los Pirineos, han encarnado de forma mayoritaria este objeto de estudio, atendiendo generalmente a su descubrimiento científico, sociocultural, estético y patrimonial durante la modernidad, a las connotaciones ideológicas e identitarias depositadas en sus paisajes, y a las problemáticas de su conservación y gestión (Nicolson, 1963; Joutard, 1986; Walter, 1989; Broc, 1991; Saule-Sorbé, 1993; Briffaud, 1994; Berdoulay, 1995; Debarbieux, 1995; Schama, 1996; Reichler, 2002; Walter, 2005; Beattie, 2006; Saule-Sorbé, 2010; Bertrand y Briffaud, 2011; Anderson, 2012). Asimismo, no han sido pocas las áreas montañosas extraeuropeas cuyos imaginarios colectivos y atribuciones simbólicas han sido analizados en diversos trabajos (Bernbaum, 1997; Siganos y Vierne, 2000; Thomas, 2004; Frolova, 2006; Blake, 2008; Della Dora, 2011).

La geografía española también ha sido sensible a la consideración del paisaje de montaña como un modelo cultural y un componente fundamental en la construcción de los idearios políticos, los relatos identitarios, el pensamiento geográfico, la estética del paisaje y los imaginarios geográficos en nuestra historia moderna y contemporánea (Titos Martínez, 1997; Martínez de Pisón, 2000; Ortega Cantero, 2002; Martínez de Pisón, 2004; González Trueba y Serrano Cañadas, 2007; Titos Martínez y Piñar Samos, 2009; Martínez de Pisón, 2012; Cornejo Nieto, 2015a). Las investigaciones más numerosas al respecto han sido aquellas que han estudiado las metáforas forjadas en torno a los paisajes de la Sierra de Guadarrama y del Pirineo catalán, aun cuando sus contenidos han encarnado enfoques y discursos muy distintos sobre el encuentro social, cultural e ideológico con estos espacios de montaña. Por un lado, estas investigaciones han subrayado el papel metafórico que la imagen de la montaña del Guadarrama ha tenido en la fundación institucional y epistemológica de la geografía española moderna, influida tanto por el ideario krausista como por sus prácticas pedagógicas excursionistas (Mollá Ruiz-Gómez, 1992; Martínez de Pisón, 1998a; Ortega Cantero, 2001, 2006, 2012). Por otro lado, estos trabajos han analizado la función que los imaginarios formados a partir de los paisajes pirenaicos y prepirenaicos catalanes han tenido en las narrativas oficiales de la identidad nacional y del nacionalismo en Cataluña (Nogué y Vicente, 2004; Nogué, 2005; Tort i Donada, 2007). 
Por otra parte, han aparecido otros trabajos que, de manera más específica, han prestado atención a la historia del acercamiento físico y activo a la alta montaña desde múltiples ángulos. Dichos estudios han desvelado diferentes perspectivas del alpinismo deportivo - especialmente el anglosajón decimonónico-, insertadas en discursos que han oscilado entre la influencia de la idea de lo sublime en las primeras ascensiones enmarcadas en el turismo alpino de época victoriana (Robertson, 1977; Colley, 2010), la teatralización de las expediciones a las cumbres dentro de la industria británica del entretenimiento de masas (Hansen, 1995; Ring, 2000: 46-50) y las relaciones de género en los clubes alpinos (Morin, 1999; Moraldo, 2013). Mayoritariamente, se ha querido ver en el alpinismo una práctica susceptible de vehicular las retóricas patrióticas e imperialistas de connotaciones masculinas desplegadas por los clubes nacionales de montañismo, constituidos, en Europa, a partir de la segunda mitad del siglo XIx (Lejeune, 1988; Hansen, 1991; Schama, 1996: 503-508; Ring, 2000: 65-78; Drouet, 2005; Holt, 2008; Hansen, 2013). De este modo, se ha tendido a afirmar que las montañas se transformaron, desde entonces, en espacios competitivos «de desafío muscular y masculino, de aventura competitiva» y deportiva (Cosgrove y della Dora, 2008: 4). Como ha mostrado Peter Hansen (1995: 313), la fundación del Alpine Club inglés en 1857 contribuyó a cultivar el sentido de la masculinidad, categoría de la Inglaterra victoriana «que incluía elementos de fuerza o salud física, cualidades patrióticas o militares, tradiciones de caballerosidad y honor, y códigos de conducta morales o espirituales». Las «cualidades heroicas» del hombre victoriano se erigieron como los grandes signos de la identidad nacional británica, que fueron elevadas a «símbolos culturales» de la virilidad, «el patriotismo, el carácter nacional y el poder imperial» de la nación (Hansen, 1995: 314).

El montañismo de connotaciones patrióticas no fue una práctica exclusiva de las asociaciones y clubes anglosajones o franceses. En España, la ascensión a la montaña estuvo también impregnada de un discurso de identidad nacional, el cual contribuyó de manera significativa a la construcción de los imaginarios patrióticos peninsulares. Recientemente, Nicolás Ortega Cantero (2014) ha considerado el papel de la primera sociedad alpinista española (el Club Alpino Español, fundado en 1906) y de la Sociedad Española de Alpinismo Peñalara como plataformas difusoras del montañismo institucionista del último cuarto del siglo XIX, que adquirió un carácter de "afirmación patriótica, de caracterización de una cultura propia, de índole nacional, enraizada en la historia interna de España» (Ortega Cantero, 2001: 174). En el caso de Cataluña, las connotaciones ideológicas del conocimiento de la montaña han funcionado como uno de los mecanismos retóricos más influyentes en el pensamiento catalanista desde la segunda mitad del siglo XIx. Como ha apuntado Jordi Martí Henneberg, la idea alegórica de la «muntanya» vehiculó «un sentimiento más general de afirmación cultural propia», encarnando «una determinada entidad histórica» y un repositorio geográfico "de un alma colectiva recuperable en el conocimiento directo del territorio" (cit. en Martínez de Pisón y Álvaro, 2002: 74). Dentro del discurso de un nuevo sentimiento nacional, montañas 
como el Canigó, el Pedrafroca y el macizo de Montserrat adquirieron un sentido "mítico, regenerativo y casi iniciático», alzándose como «reducto[s] de los valores morales que alimentan el carácter y la identidad del pueblo catalán» (Nogué, 2005: 155-156).

Sin embargo, no fueron únicamente las narrativas patrióticas masculinas de conquista ni de afirmación de las identidades nacionales las que estuvieron presentes en el ejercicio del alpinismo europeo durante el siglo xIx. De forma paralela, aparecieron otras retóricas minoritarias que acompañaron a la práctica del montañismo, favorecidas por un tipo de montaña particular y por un tipo de expedicionista dotado de un trasfondo más intelectual. Dichas retóricas estuvieron vinculadas con los significados históricos y mitológicos enraizados en el territorio. De este modo, según Veronica della Dora (2008), las montañas del Mediterráneo oriental no solo se han visto como retos deportivos para el montañista, sino también como depósitos geográficos de una densa historia y una conocida mitología clásica, que fueron recuperadas mediante procedimientos visuales, corpóreos y performativos, generados por el contacto físico con la cumbre.

Las cumbres principales de Sierra Nevada, lejos de ser interpretadas como lugares de afirmación de un sentimiento de identidad regional o nacional, serían también percibidas y ascendidas como repositorios geográfico-históricos, vinculándose, en su caso, con los significados históricos de la antigua Granada islámica enraizados en el territorio, tal como tratará de mostrar el presente artículo.

\section{El primer montañismo en Sierra Nevada}

El objeto de estudio del presente artículo, Sierra Nevada, también motivó diversas modalidades de acercamiento físico a sus cumbres que ofrecieron interpretaciones originales de sus particularismos topográficos, históricos y paisajísticos. En este sentido, la elaboración de una historia sistemática del macizo se debe al historiador Manuel Titos Martínez, quien ha investigado diversos aspectos de la Sierra vinculados a la economía y a la sociedad granadinas, insistiendo especialmente en las actividades del turismo, los deportes de invierno y otras formas de montañismo (Titos Martínez, 1992, 1997, 2004). En sus publicaciones más recientes, el historiador se ha centrado en los aspectos relacionados con las actividades del montañismo y del esquí, mostrando la labor de las asociaciones locales de montañismo en la promoción de la Sierra, los procesos de regularización del esquí penibético y la organización de megaeventos multitudinarios, como las pruebas deportivas internacionales (Titos Martínez, 2014). Con ello, Titos Martínez ha compuesto un relato histórico del "penibetismo», en el que presenta la transformación de Sierra Nevada en función de las actividades específicas que han modelado los usos deportivos y lúdicos del macizo a lo largo de su historia contemporánea.

Más recientemente, se ha llevado a cabo una investigación de carácter hermenéutico sobre los modelos históricos de representación derivados de los 
diferentes sistemas de conocimiento del macizo desde el siglo XvI hasta principios del xx (Cornejo Nieto, 2015a). Esta tesis doctoral inédita dedica sendos capítulos a los modelos narrativos y de representación forjados a partir de la actividad física del montañismo y el excursionismo nevadenses. A partir del análisis de aquellos modelos, esta contribución plantea una revisión de la historia del primer montañismo y excursionismo de Sierra Nevada aparecidos a lo largo del siglo xIx, según la cual las primeras prácticas alpinistas llevadas a cabo en el macizo nevadense fueron configuradas a partir de la asimilación de los discursos patrióticos y masculinos del montañismo foráneo practicado en la cordillera alpina. En la llamada Edad de Plata del alpinismo, fechada entre 1865 y 1882, los jóvenes montañeros se hallaron en la fase final de la exploración de los Alpes, razón por la cual tuvieron que «ir en busca de picos vírgenes en otras partes del mundo" (Thompson, 2011: 57-58). Si bien las montañas de altitudes superiores a los picos alpinos, como los Andes o el Himalaya, se encontraron entre los destinos preferidos por las nuevas generaciones de montañeros, el Alpine Club británico mostró su interés por coronar las cumbres de Sierra Nevada en sus publicaciones anuales (George, 1866: 368). Debido a su notable altitud, Sierra Nevada contaría con todo lo necesario para llamar la atención de alguna expedición del club británico (figura 1). Así, alpinistas como John Ormsby y Charles Packe podrían hacer de la Sierra un nuevo espacio alpino a pequeña escala, donde poner a prueba sus dotes físicas y seguir llevando el sentimiento victoriano de masculinidad y patriotismo a los lugares más remotos del continente, como aún seguían siendo, por entonces, las montañas del sur de la península Ibérica.

Sin embargo, en el siglo XIX, a medio camino entre la evocación del modelo de montaña continental encarnado por los Alpes y la progresiva conciencia de sus especificidades geográficas como un macizo de alta montaña mediterránea (Cornejo Nieto, 2014, 2015b), Sierra Nevada constituiría también un buen ejemplo de la construcción de aquellas retóricas surgidas de la evocación de la historia que explicaron el contacto con un tipo de sistema montañoso que no siempre se correspondía con el canon alpino. La considerable importancia, tanto real como imaginada, del macizo en la historia islámica del antiguo Reino de Granada, su patente proximidad a la ciudad nazarí y su marcada ubicación geográfica meridional influyeron igualmente en las visiones de algunos de los viajeros que emprendieron la subida a las cumbres nevadenses a lo largo del siglo XIX, visiones que quedaron al margen de las retóricas identitarias y nacionalistas de conquista de las cumbres. A través de la recuperación de tres figuras fundamentales de la exploración decimonónica de Sierra Nevada — los viajeros británicos Sir Arthur de Capell Brooke y Robert Dundas Murray, y el viajero alemán Máximo Hertting-, este artículo analiza la relación entre la ascensión a las cumbres del macizo y la rememoración de su historia medieval islámica, reconsiderando, con ello, la vinculación entre la proyección subjetiva de la memoria y el paisaje como repositorio de la misma.

Para ello, el artículo se hace eco, en primer lugar, de las líneas principales de investigación que se han dado en la geografía y otras ciencias humanas con 
Figura 1. John ORMSBY: Sketch map of the Sierra Nevada, 1867

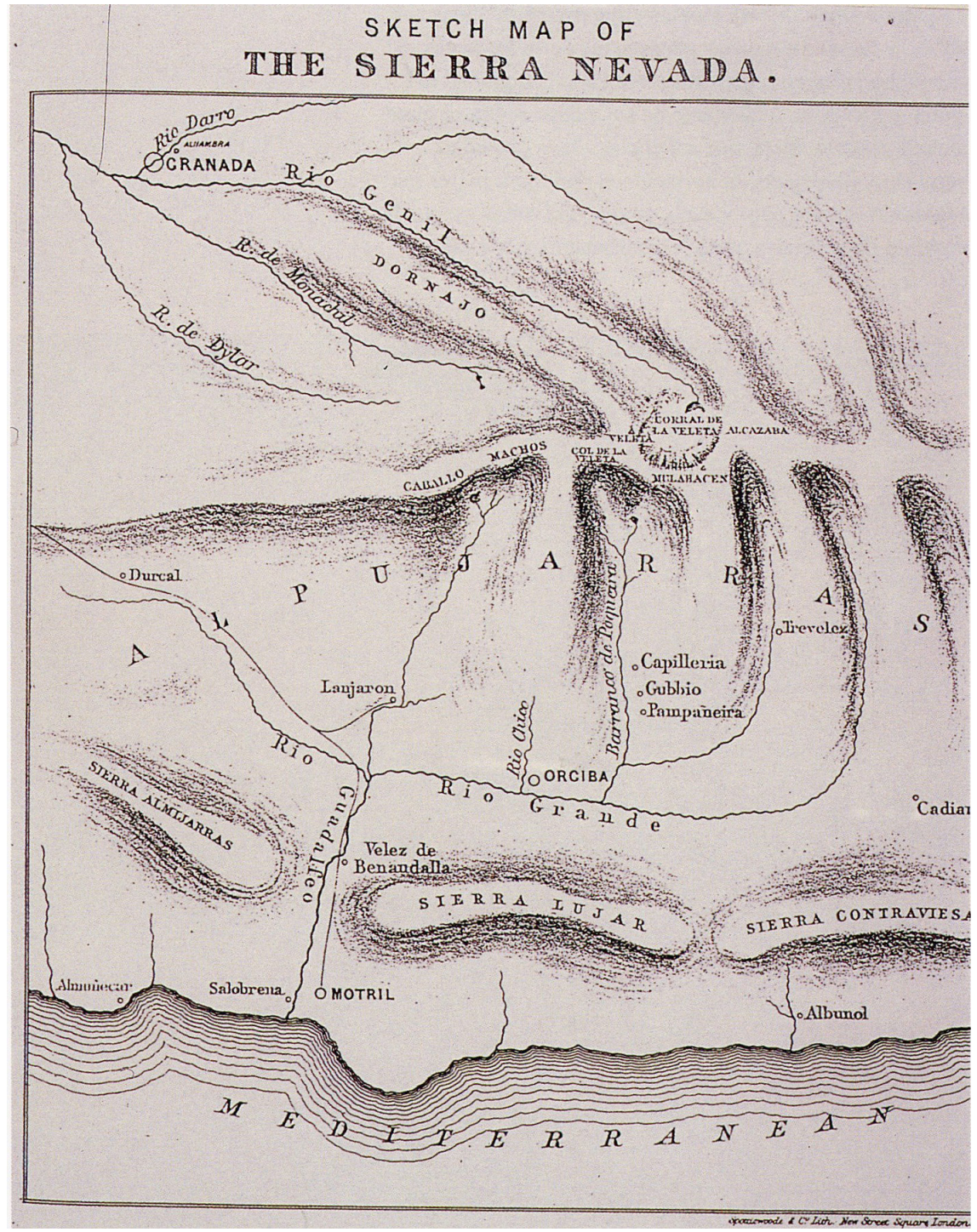

Fuente: J. ORmsBy, «The Sierra Nevada», The Alpine Journal, III, 1868. Croquis de una de las primeras expediciones británicas a Sierra Nevada organizadas por el Alpine Club.

respecto a la relación entre la memoria y el espacio geográfico. En segundo lugar, utilizando estos trabajos como marco teórico principal, se estudian las interpretaciones de la ascensión a las cumbres de Sierra Nevada ofrecidas por los viajeros mencionados. Así, se propone una nueva perspectiva de la historia 
del montañismo nevadense nunca antes planteada por la geografía cultural española, puesto que se presenta una conceptualización de la alta montaña nevadense como un espacio geográfico de unión entre el pasado (medieval islámico) y el presente (del siglo xix) de aquellos viajeros. De este modo, se pretende mostrar cómo las condiciones históricas del periodo islámico de la Sierra, insertas en el conjunto territorial del antiguo Reino de Granada, contribuyeron a crear unos modelos retóricos de montañismo muy particulares, alejados del relato convencional del alpinismo como una actividad esencialmente patriótica y nacionalista de conquista de los espacios extremos del continente europeo y peninsular. Asimismo, el artículo expone la importancia de este hecho para definir los rasgos específicos de Sierra Nevada en su diferenciación con respecto a las grandes cordilleras continentales, las cuales habían servido de modelos en la primera interpretación geográfica del macizo durante la modernidad.

\section{La espacialidad de la rememoración: geografía, paisaje y memoria}

Los estudios sobre la proyección subjetiva de la memoria y la imaginación en los territorios y paisajes son abundantes, contando incluso con algún ejemplo señero desde hace ya tiempo. Uno de los pioneros en tratar estos temas dentro de la propia disciplina de la geografía, David Lowenthal, ya abordó, en su célebre artículo de 1961, "la relación entre el mundo exterior y las imágenes de nuestra cabeza». Lowenthal sugirió que «toda imagen e idea sobre el mundo está compuesta de la experiencia personal, el aprendizaje, la imaginación y la memoria», poniendo de relieve el interés por la subjetivación del espacio y las imágenes de la memoria que se producen en los procesos relacionales entre los individuos y los lugares, no solo a través de la visión, sino también mediante un acto multisensorial sinestésico (1961: 241, 260, 244). «Necesitamos el pasado —escribía el geógrafo británico en otro lugar (Lowenthal, 1975: 5, 13) — para tratar los paisajes del presente», y señalaba, además, que el patriotismo funciona como un «estímulo» fundamental en la preservación del pasado: «la historia en el paisaje representa con frecuencia sólidos ideales nacionales».

Precisamente en esta línea, estudios más recientes dentro de la geografía cultural han tendido a indagar en cuestiones relacionadas con los vínculos entre el paisaje o el territorio (y sus representaciones) y los mecanismos colectivos de la memoria y la identidad nacional, lo que Stephen Daniels (1993) denominó las «topografías patrióticas», o François Walter (2004), las «figuras paisajísticas de la nación" (véase también Olwig, 1993; Hooson, 1994; Johnson, 1997; Mels, 1999; Darby, 2000; Whelan y Moore, 2006). Como ha apuntado Jacobo García Álvarez (2013: 412), «las interpretaciones románticas de la nación [...] han vinculado estrechamente la identidad nacional con el territorio, la naturaleza y el paisaje», viendo, en el primero, un «receptáculo del pasado en el presente» $y$, en el último, «una expresión (material y simbólica) de la historia de los grupos humanos». Con ello, se ha otorgado un significado colectivo de carácter identitario a unos paisajes y lugares determinados, "convirtiéndolos en lugares de memoria y en símbolos de la historia y el carácter nacional» (García 
Álvarez, 2013: 412), que, como también ha afirmado Joan Nogué (2005: 151), «representan e identifican los valores nacionales, la esencia de la nación» (véase también Nogué y Vicente, 2004; Ortega Cantero, 2005).

El conjunto de tales valores esenciales de identidad de una nación, trasladados de forma simbólica al paisaje o, más ampliamente, al espacio geográfico, ha sido lo que ha dado lugar al archiconocido concepto de "lugar de memoria», acuñado por el historiador francés Pierre Nora, y definido como «toda unidad significativa, de orden material o ideal, de la que la voluntad de los hombres o el trabajo del tiempo ha hecho un elemento simbólico del patrimonio de la memoria de una comunidad cualquiera» (Nora, 1997, II: 2.226). De forma más específica, y en un sentido más estrictamente espacial, tales lugares pueden ser considerados, según Nora, «lugares de memoria topográficos». Los paisajes naturales interpretados como símbolos de la nación emergen entonces como productos culturales compartidos por un mismo pueblo, cuyos posos se encuentran en la memoria, los mitos y las obsesiones recurrentes, los cuales son continuamente reactivados, transformados y reinterpretados mediante diversas políticas culturales y medioambientales (Schama, 1996). Sirviéndose del concepto de Nora — así como de las consecuentes políticas de memoria que entraña la recuperación oficial (e interesada), la patrimonialización, la promoción y la gestión de tales lugares (véase Legg, 2005; García Álvarez, 2009)—, la propia academia española ha examinado con interés las retóricas ideológicas, políticas y simbólicas motivadas por determinados lugares y paisajes que se han querido ver como enclaves fundamentales en la construcción de la nación, generalmente desde un punto de vista castellano-céntrico (Pena López, 1983; Martínez de Pisón, 1998b; Morales Moya y Esteban de Vega, 2005; García Álvarez, 2007; Ortega Cantero, 2007; Ortega Cantero y García Álvarez, 2009; García Álvarez, 2013).

Sin embargo, otros geógrafos culturales, particularmente dentro de la academia anglosajona, se han interesado por las dimensiones espaciales de la memoria, no tanto a través de los procesos que se dan en sus políticas, vehiculados por los grandes relatos a escala nacional, sino de cuestiones relacionadas con la materialidad y la subjetividad en ámbitos más locales, representados por pequeñas comunidades. En este sentido, Caitlin DeSilvey ha investigado los "procesos de rememoración cultural» que se dan en una comunidad mediante la experimentación con distintos «materiales históricos residuales» (2007: 404) —entre ellos, fragmentos de objetos y distintos documentos-, los cuales son complementados y contestados con historias orales de los miembros de dicha comunidad, ofreciendo así una especie de microrrelatos de historias olvidadas y cotidianas (véase también Buchli y Lucas, 2001; Lorimer y MacDonald, 2002).

Por otra parte, desde otras disciplinas, no se ha dejado de explorar la importancia que el sentido espacial tiene en la memoria, si bien esta, entendida como un proceso en el que se ve implicado todo el cuerpo a través de un acto multisensorial (como ya sugería Lowenthal), se ha formulado en términos fenomenológicos y ontológicos. A este respecto, Tim Ingold (1993: 152-153) ha sugerido que el acto de recordar «no es tanto una cuestión de recuperar una 
imagen interna, almacenada en la mente, como de involucrarse perceptivamente con el medio ambiente, que está él mismo impregnado del pasado». Según el antropólogo, «percibir el paisaje» supone, por sí mismo, «llevar a cabo un acto de rememoración». Dicha rememoración, como asimismo ha señalado Gilles Deleuze en su análisis de la teoría de la memoria de Bergson, ha de ser analizada como un "elemento ontológico» cuya existencia adquiere significación en el presente (1996: 57). Mientras que "el presente no es, [...] sino que actúa», el pasado «no ha dejado de ser». Aunque «inútil e inactivo, impasible, el pasado ES», «se confunde con el ser en sí». Si el presente "ya fue» a cada instante, el pasado "es eternamente, en todo momento", dependiente de un momento presente que lo define (Deleuze, 1996: 55). Ambos instantes, lejos de designar "dos momentos sucesivos», coexisten en el tiempo: «uno, que es el presente que no cesa de pasar; el otro, que es el pasado y que no cesa de ser». Por ello, afirma el filósofo francés, el pasado «es la ontología pura» y, por tanto, «el recuerdo puro no tiene otra significación que la ontológica» (Deleuze, 1996: 56, 59). Desde esta perspectiva, la rememoración constituye un acto físico, dinámico y espacialmente situado, es decir: a través de la «actitud dinámica del cuerpo», «el pasado se dirige hacia el presente para encontrar un punto de contacto [...] con él» y dotarse de sentido (Deleuze, 1996: 72).

Debido a su materialidad y visibilidad en el marco integral de un paisaje, los sistemas montañosos pueden funcionar como lugares capaces de traer al presente una evocación del pasado. Consideradas dentro de un contexto territorial e histórico específicos, las montañas, gracias a la percepción que en distinto grado se tiene de ellas, se comportan como puntos geográficos de contacto entre la vida presente y el momento pasado, como lugares donde se produce una continua (y contingente) rememoración. En palabras de Paul Ricoeur (2003: 63, 66), los lugares (y así también las cumbres) «permanecen como inscripciones», se erigen como «documentos», constituyendo una especie de "guardianes de la memoria personal y colectiva». Utilizando el concepto de Nora de «lugar de memoria topográfico» y las nociones dinámicas y ontológicas de Ingold y Deleuze del acto de rememoración para el análisis de las fuentes de los viajeros referidos anteriormente, el artículo explora, en lo que sigue, la interpretación de las dos cumbres más altas de Sierra Nevada (el Mulhacén y el Veleta) como puntos de unión entre el pasado medieval islámico del territorio y el presente de aquellos viajeros.

\section{El Veleta y el Mulhacén: lugares topográficos para la rememoración histórica}

En época romántica, especialmente durante la década de 1830, Granada se erigió como un centro de peregrinación para los viajeros escritores anglosajones que fueron en busca de lugares de apariencia exótica, orientalizante $y$, en suma, diferente, dentro de los primeros circuitos turísticos de la modernidad (Ortega Cantero, 1990; Calvo Serraller, 1995; Vega, 2004). El paisaje de la ciudad adquirió una importante visibilidad mediática en la producción narra- 
tiva e iconográfica del viaje a la Península. Sin embargo, no fue solo la imagen orientalista de la ciudad nazarí la que circuló por la cultura británica. Condicionada por su cercanía a Granada y por su notable altitud, el macizo de Sierra Nevada también ocupó una parte importante en los relatos de viajes de aquellos autores. El viaje a Andalucía se concibió, por tanto, como un desplazamiento en el tiempo (histórico) más que en el espacio (geográfico), en busca de una aventura ubicada en un pasado cronológico y en una geografía extemporánea.

El viajero inglés Sir Arthur de Capell Brooke (1791-1858) constituyó un ejemplo paradigmático de traveller bookmaker de la época de los viajeros románticos europeos (Krauel Heredia, 1986: 83). Miembro original del Traveller's Club, cofundador del Raleigh Club en 1821 y miembro, asimismo, de la Royal Geographical Society, en la década de 1820, Capell Brooke recorrió los países nórdicos y publicó sendos relatos de gran éxito hasta 1827. Quizá por sus estancias en latitudes septentrionales, en las que fácilmente pudo evocar la oscuridad y la soledad de los paisajes sublimes, se mostró muy proclive a recorrer las montañas que encontró en su viaje por España y Marruecos. Así, puso en valor los aspectos más alpinos de las zonas montañosas del norte de África y el sur de España en sus diversos relatos de viajes, al tiempo que concilió estos paisajes con una atmósfera oriental autóctona.

En su libro Sketches in Spain and Morocco, publicado en 1831, ofreció amplias descripciones de las montañas de Gibraltar, el Atlas y las sierras andaluzas. En su recorrido por el sur de la península Ibérica, el viajero británico se acercó a Granada desde Málaga, pasando por Vélez y Alhama, siguiendo así uno de los itinerarios más frecuentados por los viajeros europeos. Al aproximarse a la Vega de Granada, Capell Brooke destacó «dos cadenas paralelas de elevadas montañas onduladas levantadas unas sobre las otras, mientras, en la lejanía, los elevados picos de la cordillera de Granada coronaban indistintamente todo el conjunto». Unas jornadas después, dejaba a la derecha «una cadena desnuda de montañas, cubierta parcialmente de nieve», indicador de que se aproximaba a lo que él denominó "los nobles Alpes de Granada» (Capell Brooke, 1831: 200, 214). A su llegada a la ciudad del Darro, Brooke se hizo eco de la visión que parecía haber estado buscando durante todo su trayecto. Desde Granada, contempló la majestuosidad que le brindaba el paisaje de Sierra Nevada: «iBajo qué aspecto tan diferente se muestra la naturaleza cuando las elevadas nieves de la Sierra Nevada aparecen de repente a la vista del viajero en su frío y tranquilo esplendor!» (Capell Brooke, 1831: 216-217).

Al contemplar Granada desde la distancia, el viajero británico estableció una importante relación visual entre la monumentalidad de la ciudad nazarí y la grandiosidad de su paisaje natural de montaña, destacando dos elementos que, desde entonces, se complementarían de manera significativa en las descripciones del paisaje de Sierra Nevada: las cumbres del macizo y las torres de la Alhambra (Capell Brooke, 1831: 218): «llegamos muy cerca de la hora del crepúsculo a la cima de las montañas, y la vista más magnifica irrumpió ante nosotros - la romántica ciudad de Granada, brillando a lo lejos, con sus torres y palacios amontonándose a lo largo de las partes escarpadas de la Sierra» (figura 2). 
Figura 2. David RoBERTS (E. Goodman, grabador): The Alhambra from the Albaycin, 1834. Grabado sobre plancha de acero

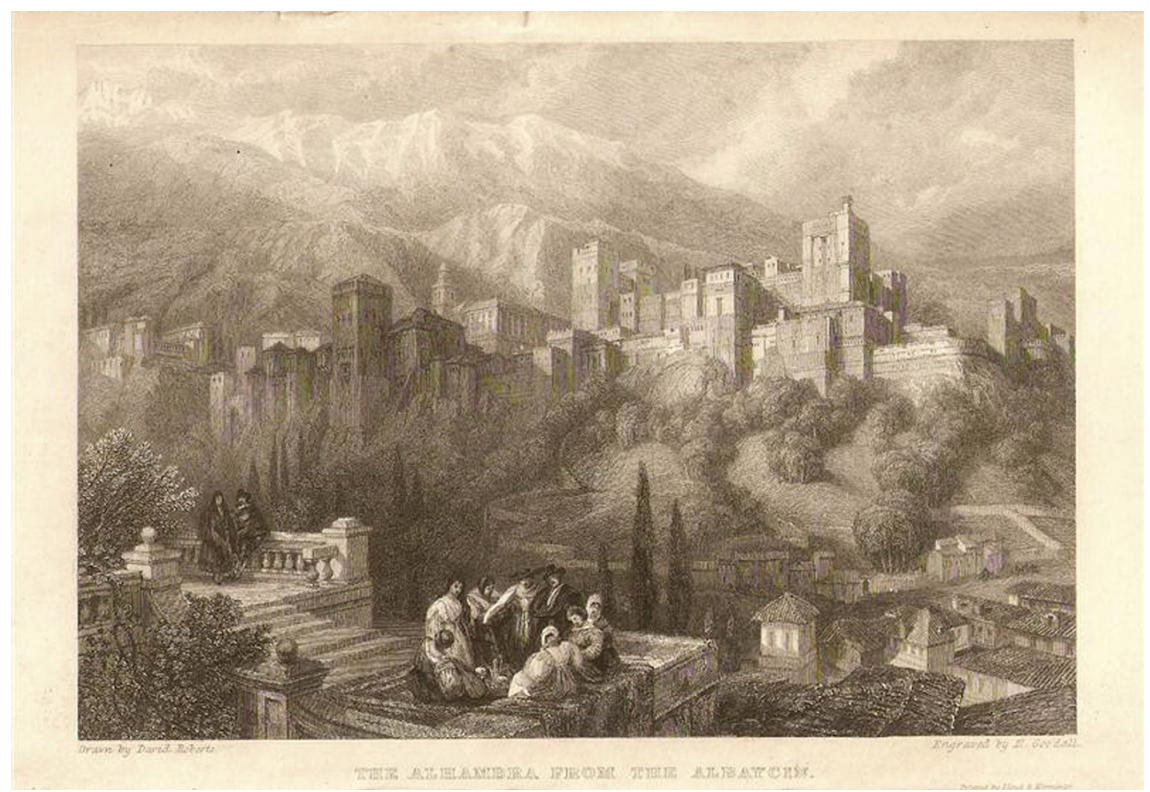

Fuente: T. Roscoe y D. RoberTs, Jennings' Landscape Annual for 1835, or The tourist in Spain. Commencing with Granada, 1835. El paisaje descrito por Capell Brooke apareció representado unos pocos años más tarde en el célebre álbum de viajes de Thomas Roscoe y David Roberts.

Pero dicha relación entre el más evidente pasado material islámico de la ciudad (los palacios nazaríes) y su paisaje geográfico más grandioso (Sierra Nevada) no fue solo vehiculado, en la imaginación de Capell Brooke, por medio de una composición visual. Consciente, como ha escrito Blake (2005: 530), de que «el significado y el mito de las montañas va más allá [...] del pico inmediatamente visible», el viajero inglés, en su ascensión a las cumbres nevadenses, evocó de manera ideal el pasado del pueblo islámico. Para ello, empleó un interesante recurso retórico que incidía en uno de los elementos específicos de la alta montaña. Capell Brooke hizo de la materialidad nival de la Sierra un testigo imperecedero de la caída del antiguo Reino nazarí de Granada a manos del régimen cristiano. Mediatizada por los propios sucesos históricos ocurridos en el territorio, Capell Brooke hacía un verdadero ejercicio de rememoración cronológica - aunque ciertamente sesgada por la maurofilia propia de la cultura británica de la época-, otorgando a Sierra Nevada el papel de testigo del pasado de toda la región. Así, una vez llegado allí, escribía Capell Brooke (1831: 216-217):

[el viajero] pisa las mismas nieves que, tres siglos atrás, fueron testigos de la caída de la orgullosa ciudad a sus pies — vio el brillo de la espada cristiana, 
y la cruz de plata plantada sobre las torres de la Alhambra; mientras el resto apenado de un pueblo valiente y noble captaba, desde los lugares de las cercanas Alpujarras, un último destello de sus otrora felices hogares, de la sonriente vega de Granada, y entonces, desconsolados, se retiraron allí en busca de un refugio en su seno.

El contacto físico con la realidad de la montaña trascendió así la «ascensión en el espacio» geográfico para convertirse «en un viajar hacia atrás en el tiempo» (MacFarlane, 2003: 53), y, una vez en la cumbre, el escritor experimentó una fuerte «expansión de la imaginación» (Nicolson, 1963: 382). En su rememoración particular a través del ejercicio del montañismo, el viajero británico resaltó aquellos elementos característicos de la alta montaña (la nieve y el hielo) que, en su propio imaginario, habían custodiado la memoria colectiva de todo el territorio. "[E]l manto congelado de estos Alpes permanece inalterado", escribía Capell Brooke (1831: 216-217), mientras, se lamentaba: «cuántas generaciones de cristianos y musulmanes han sido desterradas desde entonces». Como buen conocedor de la geograficidad de la montaña, llevó a un primer plano su materialidad como condicionante para la "perpetuación» de los hechos históricos a lo largo de los siglos (Della Dora, 2011: 19). El escritor superaba así la «mirada convencional» sobre el paisaje, recuperando, en cambio, "el mito y la memoria que yace por debajo de la superficie» (Schama, 1996: 14).

Algo más tarde, otro viajero anglosajón, el reverendo escocés Robert Dundas Murray (1816-1856), también emprendió la subida a Sierra Nevada, plasmada en su libro de viajes The cities and wilds of Andalucia, publicado en Londres en 1853. En la alta montaña nevadense, Murray quedó impresionado por la magnificencia de las paredes verticales del Corral del Veleta, que se asemejaba, según su relato, a un "precipicio semicircular» colmado de "una enorme masa de nieve», cuyas paredes rocosas se veían «tan perpendiculares como si la plomada les hubiera sido aplicadas» (Murray, 1853: 366). Desde lo alto del picacho del Veleta, escribía Murray (1853: 370): "dudo mucho de si, dentro de los límites de Europa, se puede encontrar una panorámica tan vasta y magnífica como la que se domina desde esta cumbre, [...] que casi hace realidad los sueños de la imaginación». Desde allí, denominó a la extensa llanura de la Vega de Granada «mar interior de verdor», "creciendo con sus olas de vegetación sobre los audaces promontorios que emergían de dentro de la llanura, y extendiéndose más adelante, hacia el este, en masas de exuberancia, que solo cesaban allá donde una formidable pila de montañas se elevaba contra el horizonte». De este modo, Murray asimilaba la identificación de dicho paisaje con el paraíso musulmán (Murray, 1853: 341-342): «Fue fácil de entender cómo este oasis de verdor se asemejó a un paraíso terrestre de placeres para el moro».

Maravillado por el extenso panorama descubierto desde el Veleta, Murray, en su subida a la montaña, también profundizó en la interpretación simbólica del macizo. Así, el reverendo no solo plasmó sus impresiones en términos visuales, sino que también proyectó su propia rememoración del pasado en 
todo el paisaje que rodeaba a la Sierra. En su caso, Murray hizo de la montaña un punto geográfico idóneo desde el cual podía referirse a la historia de todo el territorio circundante, recorrido por el movimiento de la mirada y evocado por su propia proyección de la memoria en el paisaje. Desde la cumbre del Veleta, Murray afirmaba (1853: 370):

[...] no solo una, sino muchas provincias y reinos pueden ser rastreados a través de un barrido de la visión; y cuando la memoria recuerda la historia y el destino de cada una de ellos, sus glorias pasadas, sus terribles convulsiones, sus influencias sobre las artes y las ciencias, los pensamientos y las opiniones, y la civilización de Europa y del mundo, es difícil decir si es el interés histórico del paisaje, o su maravillosa grandeza, el que deja la impresión más profunda en la mente.

En su visión evocadora de la historia, el reverendo escocés convertía al territorio del antiguo Reino de Granada en un repositorio material del pasado en el presente. Pero, en su caso, no lo hacía a través de la recuperación de una imagen interna, sino mediante su propia implicación perceptiva y física con el medio natural, «impregnado», como sostenía Ingold (1993), de un pasado concreto. De este modo, la rememoración de la historia por parte del viajero era reactivada a través del ejercicio activo de la ascensión y, una vez en lo alto de la montaña, del acto dinámico (y espacialmente situado) de la movilidad de la visión, que constituyó el mecanismo principal de Murray para traer, en términos deleuzianos, el pasado al presente. Ambos momentos eran conectados desde el punto geográfico de unión representado por la cumbre del Veleta. En la imaginación del viajero, el momento pasado y el momento presente parecían convivir en el mismo territorio, y el «interés histórico del paisaje», que aún dejaba "la impresión más profunda en la mente», ponía de manifiesto el carácter eterno del pasado.

Hacia 1880, fue otro viajero foráneo quien llevó a cabo la exploración alpinista a las cumbres nevadenses. El traductor y filólogo alemán Máximo Hertting acudió a Granada en 1881 y, una vez allí, participó en la excursión organizada por el montañero local Indalecio Ventura Sabatel dentro de la institución El Fomento de las Artes (Titos Martínez, 2002: 40-43). En aquella excursión de El Fomento, no se pudo realizar la ascensión al Mulhacén, por lo que Hertting decidió volver a atacar por su cuenta la cumbre más alta del macizo. Su expedición apareció publicada en el periódico El Defensor de Granada en veintidós entregas. Influido por todo el conocimiento científico que se había producido en torno a Sierra Nevada a lo largo del siglo XIX, y consciente de los factores implicados en su particular ubicación geográfica con respecto a otros sistemas de alta montaña continentales - que ya habían sido puestos de manifiesto a lo largo de la centuria por el botánico Simón de Rojas Clemente Rubio y, especialmente, por el geógrafo Moritz Willkomm-, la originalidad de la crónica de Hertting radicó en su interpretación personal del macizo desde la cumbre del Mulhacén. Al igual que había ocurrido con el Veleta en los casos 
Figura 3. F. PRUDENT (a partir de una fotografía del Dr. Bide): Les grands sommets de la Sierra Nevada: Vue prise du Pic del Cuervo, 1893. Dibujo a plumilla

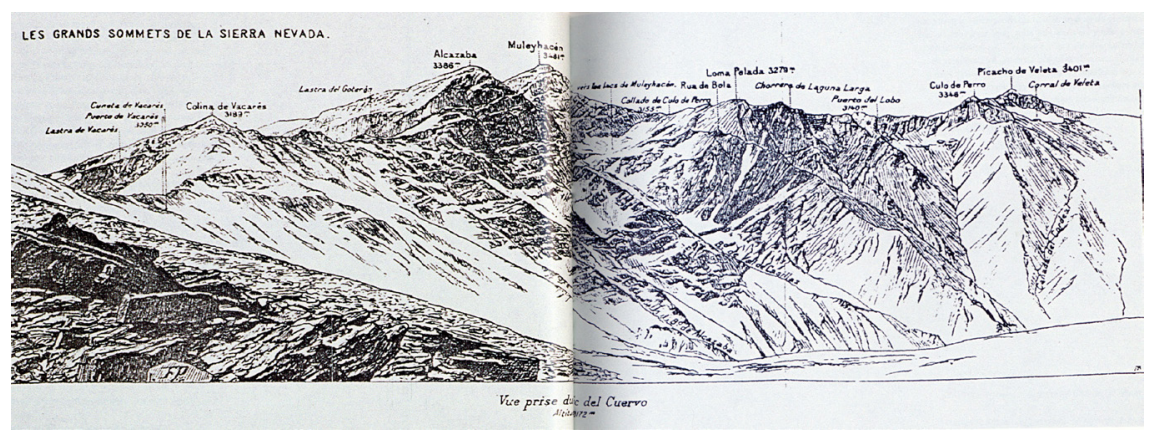

Fuente: Dr. BIDE, «Deuxième excursión dans la Sierra Nevada», Annuaire du Club Alpin Français, XX, 1894. Aunque la crónica montañera de Hertting no presentaba ningún material gráfico, una expedición francesa posterior del Club Alpino galo fotografió e ilustró varias vistas panorámicas y parciales de las cumbres, entre ellas, el cordal principal del macizo, descrito en la crónica del viajero alemán.

de Capell Brooke y Murray, la cota culminante del macizo se alzó, para el montañero alemán, como un lugar de rememoración del pasado histórico del antiguo Reino islámico de Granada.

Hertting acometió la subida al Mulhacén por la vertiente norte, remontando el Genil por la Vereda de la Estrella, subiendo después hasta la Laguna del Mulhacén y alcanzando la cumbre desde allí. Al comienzo de su crónica, el viajero alemán presentaba la magnitud de su empresa alpinista, ofreciendo al lector, en su movimiento vertical de ascensión, la alineación de las altas cumbres que conforman el cordal principal de Sierra Nevada, explicitando, incluso, las altitudes de cada montaña. Mientras que las formaciones montañosas de materiales calizos «no alcanzan más altura que 2.300 metros», escribía Hertting (1882a), sobre estas «se levanta una cresta granítica de 3.000 metros de altura media, sobre la cual se elevan seis picos de más de 3.000 metros, a saber: el Mulhacén 3.481 metros sobre el nivel del mar, el Veleta que mide 3.428, el Alcazaba 3.181, los Machos 3.200, el pico del Caballo 3.078, y la punta de Vacares 3.075» (figura 3).

Por momentos, su narración se correspondió al de una auténtica expedición alpinista. Sobre el Corral del Veleta, Hertting subrayó el notable estatus de Sierra Nevada dentro de las cordilleras del continente, otorgándole la potente imagen que merecía como el segundo sistema montañoso más alto de Europa. Para ello, incidió en aquellos elementos que configuraban al macizo su carácter específico de una gran cadena montañosa, justificando así su exploración a la alta montaña nevadense. Según la visión del montañero, el antiguo glaciar del Veleta, con su acumulación de nieve y hielo, y su aspecto de enorme sima colgada sobre la segunda cumbre más elevada de la Sierra, presentaba una imagen puramente alpina (Hertting 1882a): «En la planta o asiento del corral del Veleta que es una porción de la inmensa y profundísima cavidad de 600 
Figura 4. Franz SCHRADER (a partir de una fotografía del Dr. Bide): Picacho et partie supérieure du Corral de la Veleta vue prise du bord occidental du Corral, 1892

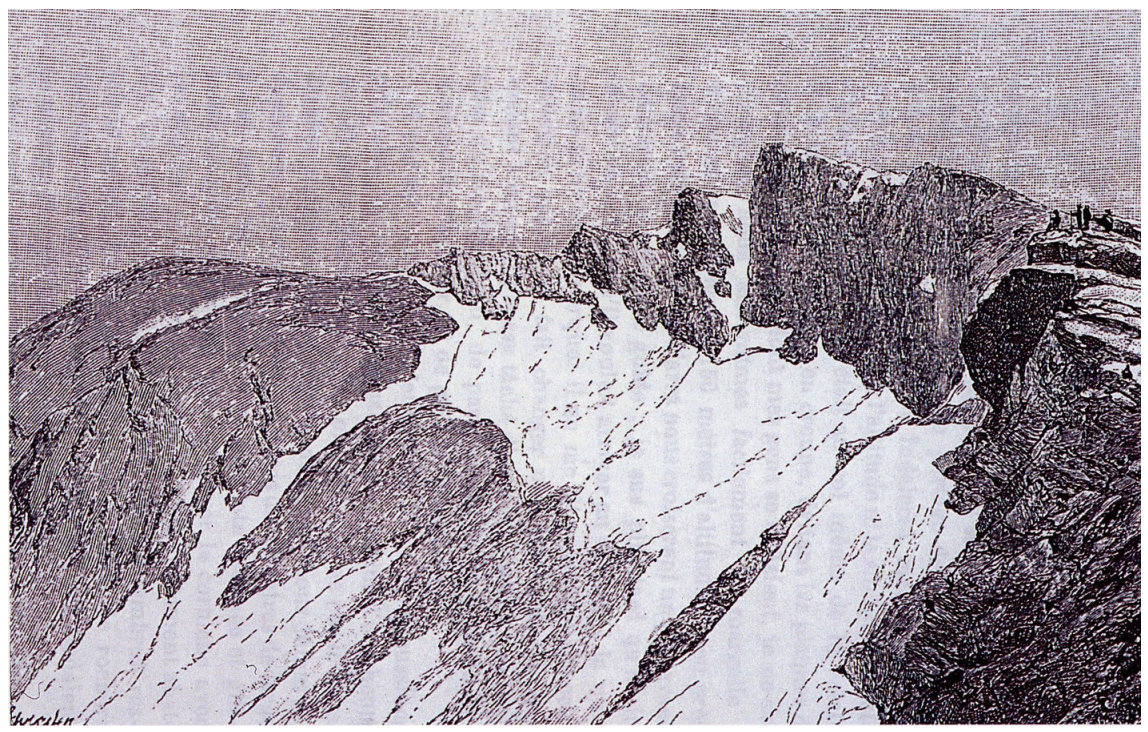

Fuente: Dr. BIDE, «Excursion à la Sierra Nevada et ascension du Picacho de la Veleta», Annuaire du Club Alpin Français, XIX, 1893. La descripción del Corral del Veleta ofrecida por la crónica de Hertting pareció verse reflejada en el dibujo del geógrafo y pintor francés Franz Schrader, publicado en la crónica de la expedición francesa de 1892.

metros, que forma un circo o anfiteatro entre el Mulhacen y el Picacho de Veleta, está situada la mole de un banco de hielo de 2 á 300 metros: semejante a los ventisqueros de Suiza, el ventisquero más meridional de Europa y que dá origen al Genil, acotado por una especie de murallas que forman las rocas» (figura 4).

No obstante, a pesar de la comparación con el mundo alpino, Hertting fue consciente de las diferencias entre Sierra Nevada y la cordillera centroeuropea. Por ello, se interesó en subrayar las peculiaridades del macizo. El «sistema andaluz», reflejó en su crónica (Hertting, 1882a), «ofrece los contrastes más rápidos de altura y de profundidad», así como «las diferencias más irreconciliables del calor africano y del hielo polar», y «vejetaciones tropicales lindando casi con la pobreza vejetal del Norte». Estas características diferenciadoras suscitaron en Hertting otro tipo de proyecciones subjetivas sobre las cumbres nevadenses, distintas de las retóricas convencionales que habían hecho de los picos de los Alpes espacios de «demostración de la fuerza imperial» y de la «flama patriótica» (Schama, 1996: 464, 503). En su imaginario, el paisaje de la Sierra se vio favorecido por su latitud meridional y su cercanía al mar Mediterráneo, hecho geográfico que otorgaría al macizo unos rasgos específicos propios como lugar topográfico de una memoria singular. 
Debido a esta circunstancia, Hertting se mostró convencido de que Sierra Nevada superaba a todas las cordilleras europeas ${ }^{1}$. Esta superioridad se debía, según su criterio, a tres razones fundamentales. La primera de ellas era «su situación, en un clima casi tropical que la hace superior bajo el punto de vista del botánico», ubicación que hacía posible, además, «lo despejado de sus horizontes; lo agradable de su temperatura, [...] la frescura de su atmósfera [...], [y] la clemencia de sus noches». Junto a ello, y como segunda razón, había que considerar «la facilidad y la seguridad que ofrece al viajero» en la exploración de sus cumbres. Pero, en particular, como la tercera de las razones, Sierra Nevada aventajaba a "todos los Alpes de Europa" por el pasado histórico del que estaban impregnadas sus cumbres, por «la historia de aquel infeliz pueblo morisco que ha otorgado a las montañas y a los valles de la Nevada un mágico encanto que será imperecedero como sus rocas» (Hertting, 1882c).

La valoración de Hertting del pasado del Reino de Granada fue suscitada durante su ascensión a Sierra Nevada, desde cuya cumbre interpretaría el macizo como un gran repositorio geográfico del antiguo esplendor del periodo islámico. Consciente, por tanto, de la tipología mediterránea de la Sierra y de su específico trasfondo histórico (ausente en otras cordilleras europeas), Hertting no solo llevó a cabo un movimiento vertical de superación de la altitud de la montaña, sino que también realizó un desplazamiento virtual en el tiempo. A través del acto físico de la ascensión al Mulhacén, el montañero entró en contacto con la historia, llevando a su presente el pasado del territorio e interpretando la cumbre como un punto de unión entre el presente y el pasado en un acto de rememoración de la historia islámica de todo el territorio en el que se circunscribía el macizo. Con ello, convertía el ejercicio del alpinismo en un acto nemónico, arraigado en su percepción del paisaje y en su propio contacto corpóreo con la montaña (Hertting, 1882c):

Cuando se encuentra uno en el rey de los montes del antiguo Reino de Granada, en el que, según la tradición, se perpetuó la memoria del último rey independiente del imperio morisco, en el Mulhacén, erguido entre Veleta y Alcazaba como entre dos guardianes de honor, con la vista a través del espejo azul del Mediterráneo de la bermeja costa africana, sobre cuyas líneas suavemente ondeadas se destacan en lo alto de la bóveda celeste los conos cubiertos de nieve del sublime Atlas [...], no se puede menos de saludar con emoción a este hermano de la Sierra Nevada, el Atlas gigantesco, que arropado en su blanco alquicel de nieve rivaliza en altura y en aspecto con su granadina hermana española; y entonces, cuando las ardientes brisas del suelo africano vienen a besar las nieves de esta Sierra; trayendo ente sus ondas los suspiros de

1. En realidad, con esta convicción, Hertting estaba secundando la tesis del geógrafo y botánico alemán Moritz Willkomm (cuya obra conocía muy bien), que había estudiado profundamente el macizo de Sierra Nevada y otras montañas peninsulares entre los años 1844 y 1846 (véase Bosque Maurel, 1993; Titos Martínez, 1997, I: 161-171). Según la idea de Willkomm, no había, en la península Ibérica ni en todo el continente europeo, otra zona geográfica que se pudiera parangonar con la de Granada en altitud, formación y «romanticismo», así como tampoco «respecto a la ubicación geográfica y el clima» (Willkomm, 1993: 53). 
un pueblo a quien no le es dado olvidar el paraíso que sus padres perdieran, porque así estaba escrito, parece como si el apasionado beso de esas brisas y al mágico ardor de esos suspiros, derritieran en lágrimas las purísimas nieves para fertilizar las vegas granadinas, murmurando en arroyos, cascadas y fuentes la brillantísima y trágica historia del morisco pueblo, cuya memoria existirá, mientras existan esas soberbias Sierras y esas murmuradoras cascadas y esos paradisiacos vergeles del suelo andaluz!

En el mismo techo de la Sierra, Hertting recuperaba la memoria del pueblo musulmán, con lo que convertía la cumbre más alta de la Península en un lugar topográfico para la rememoración. Al mismo tiempo, haciendo referencia a la mediterraneidad del macizo, convertía a la montaña en un «nodo de [...] cultos y mitos antiguos» donde dotar al pasado de sentido (Della Dora y Terkenli, 2012: 140). Ayudado por la evocación visual del Atlas como «hermano» de Sierra Nevada, Hertting realizó la unión imaginaria de ambas cordilleras a través del «espejo azul del Mediterráneo», planteando un ejercicio completo de rememoración del antiguo esplendor oriental de Granada y su Sierra, así como una conexión geográfica entre el pasado del macizo y el presente del mundo oriental africano. Pero, a diferencia de los viajeros británicos, Hertting supo dotar al presente de una evidente realidad geográfica mediante la descripción de la ordenación paisajística de las cotas más bajas del territorio granadino, resultado de la aportación nival de Sierra Nevada. De este modo, si el tiempo pasado era encarnado por el antiguo esplendor de época islámica, evocado a través del carácter oriental de la Sierra - a lo que contribuía su proximidad con la «bermeja costa africana» y sus montañas-, el tiempo presente se manifestaba en las tierras fértiles de las vegas, dependientes del depósito hídrico encarnado por el macizo. Al tiempo que el Mulhacén fue interpretado por la imaginación del montañero alemán como un lugar de rememoración histórica donde coexistían el pasado y el presente, la yuxtaposición de ambos momentos se revelaban en la realidad del paisaje, lo cual daba forma a la geografía del territorio de Granada.

\section{Conclusiones}

El espacio geográfico se comporta como un receptáculo material de la proyección subjetiva de la memoria de los individuos y los grupos humanos. Así como las llamadas «topografías patrióticas» tienen capacidad para generar y articular los discursos de la identidad nacional, las particularidades ambientales, topográficas y materiales del paisaje también provocan la reactivación de la memoria y la imaginación a través del encuentro corpóreo y multisensorial del individuo con el territorio desde una dimensión fenomenológica y dinámica. En este sentido, las actividades físicas realizadas en los espacios extremos de alta montaña constituyen ejemplos sugerentes de este encuentro dinámico, activo y espacialmente situado con la realidad geográfica de las cotas altas de las cordilleras. Es allí donde, a través de un proceso de estimulación de la memoria 
en el que se ve implicado todo el cuerpo, se produce un acto de rememoración de la historia. De este modo, las montañas aparecen, en términos de Nora, como atrayentes «lugares de memoria topográficos» donde, en términos deleuzianos, la condición eterna del pasado se mueve hacia el presente y encuentra un punto real (y geográfico) de contacto, con lo cual se dota de significación. En los lugares de memoria, por tanto, lejos de emerger únicamente un pasado colectivo identificado con los grandes relatos identitarios, el pasado también se manifiesta, «ES», en el presente, y aparece, de esta manera, como un «elemento ontológico".

Las cumbres de Sierra Nevada ofrecen un significativo ejemplo de tal encuentro entre el pasado y el presente a través del conocimiento real —esto es, físico y activo- de sus particularismos, conocidos, o acaso intuidos, por determinados montañistas foráneos del siglo XIX. Entre sus especificidades geográficas, las cuales comenzaron a ser definidas durante aquella centuria, y a cuyo descubrimiento contribuyó su ubicación geográfica meridional y su patente proximidad a la ciudad nazarí, figuran su pertenencia a una zona macroclimática de influencia mediterránea y la caracterización islámica del macizo como parte de la historia del antiguo Reino de Granada. Si bien la cordillera alpina se tomó entre los montañistas como un reto hercúleo, esencialmente deportivo, donde desarrollar los valores morales masculinos y patrióticos de las naciones europeas, el caso de Sierra Nevada, debido precisamente a dichas particularidades, presenta una alternativa a tales retóricas. Como ha mostrado el artículo, tres viajeros montañistas, Capell Brooke, Murray y Hertting, se sirvieron de la evocación del pasado islámico para trazar una conceptualización del macizo como una montaña de reminiscencias musulmanas. Cada uno de una manera diferente, aunque partiendo todos ellos del movimiento vertical hacia las cumbres del Veleta y el Mulhacén, favorecieron la creación de un nuevo modelo de alta montaña, donde, gracias a la rememoración de la historia, convergieran lo occidental (europeo, el presente) y lo oriental (islámico, el pasado).

Capell Brooke utilizó un recurso retórico según el cual subrayó el elemento material de la nieve de la Sierra como un testigo perpetuo de la desaparición del antiguo Reino nazarí de Granada en su rememoración del pasado del pueblo islámico. Murray, por su parte, empleó su implicación multisensorial con la naturaleza de la montaña mediante la actividad de la ascensión y la movilidad de la visión desde la cumbre para proyectar la memoria en el paisaje del territorio de Granada y atraer así el pasado a su presente. Y, por último, Hertting, el más consciente de las diferencias de Sierra Nevada con respecto a la alta montaña europea, concibió el acto físico de la subida al Mulhacén como un ejercicio mnemónico a través del cual recuperar el pasado y entrar en contacto con la historia. Su evocación del pasado se manifestó, además, en su lectura del paisaje geográfico presente que pudo contemplar desde la cumbre, formado por las extensas vegas de los ríos que dependen de la aportación hídrica del macizo. Los tres proyectaron, en todo el paisaje que rodeaba a la Sierra, su propia rememoración del pasado. Practicaron e imaginaron las cumbres más 
altas del macizo como un lugar topográfico de rememoración del pasado histórico de la antigua Granada islámica. Convirtieron al Veleta y al Mulhacén en puntos de unión entre el presente y el pasado, en espacios geográficos desde los cuales llevar a cabo una reminiscencia de lo que podría parecer que ya no pervive, pero que, como escribe Deleuze, puede contribuir a la comprensión del presente, incluyendo, como dejó patente Hertting, el conocimiento geográfico del paisaje.

\section{Referencias bibliográficas}

Anderson, Ben M. (2012). "The construction of an Alpine landscape: Building, representing and affecting the Eastern Alps, c. 1885-1914». Journal of Cultural Geography, 29 (2), 155-183.

Beattie, Andrew (2006). The Alps: A Cultural History. Oxford: Oxford University Press.

Berdoulay, Vincent (ed.) (1995). Les Pyrénées, lieux d'interaction des savoirs (XIXedébut XXe S.). París: Éditions du Comité des Travaux Historiques et Scientifiques.

Bernbaum, Edwin (1997). Sacred Mountains of the World. Berkeley: University of California Press.

Bertrand, George y Briffaud, Serge (2011). Le paysage: Retour d'expériences entre recherche et projet. Arthous: Centre Départamental du Patrimoine.

BlAKE, Kevin (2005). «Mountain symbolism and geographical imaginations». Cultural Geographies [en línea], 12 (4), 527-531. <http://dx.doi.org/10.1191/1474474005eu339ra>

- (2008). «Imagining heaven and earth at Mount of the Holy Cross, Colorado». Journal of Cultural Geography [en línea], 25 (1), 1-30. <http://dx.doi.org/10.1080/08873630701822588>

Bosque Maurel, Joaquín (1993). «Un científico germano en Andalucía». En: Willkomm, Moritz. Las sierras de Granada (1882). Granada: Caja General de Ahorros y Monte de Piedad de Granada, 11-45.

BRIFFAUD, Serge (1994). Naissance d'un paysage: La montagne pyrénéenne à la croisée des regards (XVIIe-XIXe siècles). Toulouse: AGM, Université de Toulouse II.

Broc, Numa (1991). Les montagnes au siècle des lumières: Perception et représentation. 2. a ed. París: Comité des Travaux Historiques et Scientifiques.

Buchli, Victor y Lucas, Gavin (2001). Archaeologies of the Contemporary Past. Londres: Routledge.

Calvo Serraller, Francisco (1995). «La imagen romántica de España». En: La imagen romántica de España: Arte y arquitectura del siglo XIX. Madrid: Alianza, 15-29.

Capell Brooke, Sir Arthur de (1831). Sketches in Spain and Morocco. Londres: Henry Colburn and Richard Bentley.

Colley, Ann C. (2010). Victorians in the Mountains: Sinking the Sublime. Surrey, (Inglaterra) y Burlington (EUA): Ashgate.

Cornejo Nieto, Carlos (2014). “"Geografías de recepción” de los imaginarios geográficos alpinos: Representaciones y narrativas de Sierra Nevada (s. XIX)». Cuadernos Geográficos, 53 (1), 5-35.

- (2015a). Los imaginarios geográficos de Sierra Nevada (siglos XVI-XIX): Modelos de representación y prácticas espaciales en la circulación global del conocimiento de la montaña. Universidad Autónoma de Madrid. Tesis doctoral. 
- (2015b). «La circulación del conocimiento en la creación del discurso geográfico de Sierra Nevada en el s. XIX». Cuadernos de Investigación Geográfica, 41 (1), 231-248.

Cosgrove, Denis y Della Dora, Veronica (eds.) (2008). High Places: Cultural Geographies of Mountains, Ice and Science. Londres: IB Tauris.

DANIELS, Stephen (1993). Fields of Vision: Landscape Imagery and National Identity in England and the United States. Cambridge: Polity Press.

Darby, Wendy Joy (2000). Landscape and Identity: Geographies of Nation and Class in England. Oxford: Berg.

Debarbieux, Bernard (1995). Tourisme et montagne. París: Economica.

Deleuze, Gilles (1996). El bergsonismo. Traducido por Luis Ferrero Carracedo. 2. a ed. Madrid: Cátedra.

Della Dora, Veronica (2008). «Mountains and memory: Embodied visions of ancient peaks in the nineteenth-century Aegean». Transactions of the Institute of British Geographers [en línea], 33 (2), 217-232. <http://dx.doi.org/10.1111/j.1475-5661.2008.00296.x>

- (2011). Imagining Mount Athos: Visions of a Holy Place from Homer to World War II. Charlottesville (VA): University of Virginia Press.

Della Dora, Veronica y Terkenli, Theano S. (2012). "Cultural Geographies». En: Vogiatzakis, Ioannis (ed.). Mediterranean Mountain Environments. Chichester, West Sussex: John Wiley, 137-157.

DeSilvey, Caitlin (2007). «Salvage memory: Constellating material histories on a hardscrabble homestead». Cultural Geographies [en línea], 14 (3), 401-424. <http://dx.doi.org/10.1177/1474474007078206>

Drouet, Yann (2005). "The "CAF" at the borders: Geopolitical and military stakes in the creation of the French Alpine Club». The International Journal of the History of Sport [en línea], 22 (1), 59-69.

<http://dx.doi.org/10.1080/0952336052000314610>

FonD, Richard (1845). A Hand-book for travellers in Spain and readers at home, describing the country and cities, the natives and their manners, the antiquities, religion, legends, fine arts, literature sports, and gastronomy; with notices on Spanish history. Part I. Contaning Andalucía, Ronda and Granada, Murcia, Valencia, Catalonia and Extremadura; with travelling maps and a copious index. Londres: John Murray.

Frolova, Marina (2006). Les paysages du Caucase: Invention d'une montagne. París: Comité des Travaux Historiques et Scientifiques.

García Álvarez, Jacobo (2007). «Paisajes nacionales, turismo y políticas de memoria: Toledo (1900-1950)». Ería, 73-74, 193-212.

- (2009). "Lugares, paisajes y políticas de memoria: Una lectura geográfica». Boletín de la Asociación de Geógrafos Españoles, 51, 175-202.

- (2013). «Paisaje, memoria histórica e identidad nacional en los inicios de la política de conservación de la naturaleza en España: De Covadonga a San Juan de La Peña». Hispania [en línea], LXXIII (244), 409-438. <http://dx.doi.org/10.3989/hispania.2013.012>

George, Hereford Brooke (1866). The Alpine Journal: A Record of Mountain Adventure and Scientific Observation. Londres: Longman, Green, Roberts, and Green.

González Trueba, Juan José y Serrano Cañadas, Enrique (2007). Cultura y naturaleza en la Montaña Cantábrica. Santander: Universidad de Cantabria.

Hansen, Peter H. (1991). British Mountaineering, 1850-1914. Harvard University. $\mathrm{PhD}$ thesis. 
- (1995). "Albert Smith, the Alpine Club, and the invention of mountaineering in mid-Victorian Britain». Journal of British Studies, 34 (3), 300-324.

- (2013). The Summits of Modern Man: Mountaineering after the Enlightenment. Cambridge (MA): Harvard University Press.

Hertting, Máximo (1882a). «En Sierra Nevada: Impresiones de un viajero alemán (I)». El Defensor de Granada, III (765) (10 de noviembre), s. p.

- (1882b). «En Sierra Nevada: Impresiones de un viajero alemán (II)». El Defensor de Granada, III (766) (11 de noviembre), s. p.

- (1882c). «En Sierra Nevada. Impresiones de un viajero alemán (XIX)». El Defensor de Granada, III (797) (12 de diciembre), s. p.

Holt, Lee Wallace (2008). Mountains, Mountaineering and Modernity: A Cultural History of German and Austrian Mountaineering, 1900-1945. Ann Arbor (MI): ProQuest.

Hooson, David (1994). Geography and National Identity. Oxford-Cambridge: Blackwell.

IngOLD, Tim (1993). «The temporality of the landscape». World Archaeology [en línea], 25 (2), 152-174. <http://dx.doi.org/10.1080/00438243.1993.9980235>

Johnson, Nuala (1997). "Cast in stone: Monuments, geography, and nationalism». En: Agnew, John (ed.). Political Geography. Londres: Routledge, 177-186.

Joutard, Philippe (1986). L'invention du Mont Blanc. París: Gallimard.

Krauel Heredia, Blanca (1986). Viajeros británicos en Andalucía de Christopher Hervey a Richard Ford (1760-1845). Málaga: Universidad de Málaga.

LEGG, Stephen (2005). «Contested and surviving memory: Space, nation and nostalgia in Les Lieux de Memoire». Environmemt and Planning D: Society and Space, 23, 81-504.

Lejeune, Dominique (1988). Les «alpinistes» en France (1875-1919). París: Comité des Travaux Historiques et Scientifiques.

Lorimer, Hayden y MacDonald, Fraser (2002). «A rescue archaeology, Taransay, Scotland». Cultural Geographies [en línea], 9, 95-102. <http://dx.doi.org/10.1191/1474474002eu235oa>

Lowenthal, David (1961). "Geography, experience, and imagination: Towards a geographical epistemology». Annals of the Association of American Geographers, 51 (3), 241-260.

- (1975). «Past time, present place: Landscape and memory». Geographical Review [en línea], 65 (1), 1-36. <http://dx.doi.org/10.2307/213831>

MacFarlane, Robert (2003). Mountains of the Mind. Nueva York: Pantheon Book.

Martínez de Pisón, Eduardo (dir.) (1998a). Madrid y la Sierra de Guadarrama [cat. exp.]. Madrid: Museo Municipal.

- (1998b). Imagen del paisaje: La Generación del 98 y Ortega y Gasset. Madrid: Obra Social Caja Madrid.

- (2000). «Imagen de la naturaleza de las montañas». En: SANz Herráiz, Concepción y Martínez de Pisón, Eduardo (eds.). Estudios sobre el paisaje. Madrid: Universidad Autónoma de Madrid, 15-54.

- (2004). «El paisaje de montaña: La formación de un canon natural del paisajismo moderno». En: Ortega Cantero, Nicolás (ed.). Naturaleza y cultura del paisaje. Madrid: Fundación Duques de Soria y Universidad Autónoma de Madrid, 53-121.

- (2012). «La montaña simbólica». Cuadernos Geográficos, 51, 8-17. 
Martínez de Pisón, Eduardo y Álvaro, Sebastián (2002). El sentimiento de la montaña: Doscientos años de soledad. Madrid: Desnivel.

Mels, Tom (1999). Wild Landscapes: The Cultural Nature of Swedish National Parks. Lund: Lund University Press.

Mollá Ruiz-Gómez, Manuel (1992). «El conocimiento naturalista de la Sierra de Guadarrama: Ciencia, educación y recreo». En: Gómez Mendoza, Josefina y Ortega Cantero, Nicolás (eds.). Naturalismo y geografía en España: Desde mediados del siglo XIX hasta la Guerra Civil. Madrid: Fundación Banco Exterior, 275-346.

Moraldo, Delphine (2013). "Gender relations in French and British mountaineering». Journal of Alpine Research | Revue de Géographie Alpine [en línea], 101 (1). <http://dx.doi.org/10.4000/rga.2027>

Morales Moya, Antonio y Esteban de Vega, Mariano (eds.) (2005). ¿Alma de España?: Castilla en las interpretaciones del pasado español. Madrid: Marcial Pons.

Morin, Karen M. (1999). "Peak practices: Englishwomen's "heroic" adventures in the nineteenth-century American West». Annals of the Association of American Geographers, 89 (3), 489-514.

Murray, Robert Dundas (1853). The Cities and Wilds of Andalucia. 3. a ed. Londres: Richard Bentley.

Nicolson, Marjorie Hope (1963). Mountain Gloom and Mountain Glory: The Development of the Aesthetics of the Infinite. Nueva York: W.W. Norton.

Nogué, Joan (2005). «Nacionalismo, territorio y paisaje en Cataluña. En: Ortega Cantero, Nicolás (ed.). Paisaje, memoria histórica e identidad nacional. Madrid: Fundación Duques de Soria y Universidad Autónoma de Madrid, 147-169.

Nogué, Joan y Vicente, Joan (2004). «Landscape and national identity in Catalonia». Political Geography [en línea], 23 (2), 113-132. <http://dx.doi.org/10.1016/j.polgeo.2003.09.005>

Nora, Pierre (dir.) (1997). Les lieux de mémoire. 3 vols. París: Gallimard, 1984-1992.

Olwig, Kenneth (1993). «Sexual Cosmology: Nation and Landscape at the Conceptual Interstices of Nature and Culture; or: What does Landscape Really Mean?». En: Bender, Barbara (ed.). Landscape: Politics and Perspectives. Providence: Berg, 307-343.

Ortega Cantero, Nicolás (1990). «El paisaje de España en los viajeros románticos». Ería, 22, 121-137.

- (2001). Paisaje y excursiones: Francisco Giner, la Institución Libre de Enseñanza y la Sierra de Guadarrama. Madrid: Raíces.

- (2002). «La valoración institucionalista del paisaje de la Sierra de Guadarrama». En: Ortega Cantero, Nicolás (ed.). Estudios sobre historia del paisaje español. Madrid: Universidad Autónoma de Madrid y Fundación Duques de Soria, 169-186.

- (ed.) (2005). Paisaje, memoria histórica e identidad nacional. Madrid: Universidad Autónoma de Madrid y Fundación Duques de Soria.

- (2006). «Paisaje y símbolo: La imagen literaria de la Sierra de Guadarrama». En: Ortega Cantero, Nicolás; López Ontiveros, Antonio y Nogué i Font, Joan (eds.). Representaciones culturales del paisaje: Y una excursión por Doñana. Madrid: Universidad Autónoma de Madrid, 97-120.

- (2007). «La valoración patrimonial y simbólica del paisaje de Castilla (18751936)». Ería, 73-74, 137-159.

- (2012). «Naturaleza, cultura y símbolo: La imagen de la montaña de Peñalara en el paisajismo español moderno». Cuadernos Geográficos, 51, 96-113. 
- (2014). «Montañismo y valoración del paisaje: La Real Sociedad Española de Alpinismo Peñalara (1913-1936)». Ería, 95, 253-279.

Ortega Cantero, Nicolás y García Álvarez, Jacobo (2009). «Paisajes y lugares de memoria: Covadonga y El Paular». En: Martínez de Pisón, Eduardo y Ortega Cantero, Nicolás (eds.). Los valores del paisaje. Madrid: Fundación Duques de Soria y Universidad Autónoma de Madrid, 45-94.

Pena López, Carmen (1983). Pintura de paisaje e ideología: La Generación del 98. Madrid: Taurus.

ReIChler, Claude (2002). La découverte des Alpes et la question du paysage. Ginebra: Georg.

Ricoeur, Paul (2003). La memoria, la historia, el olvido. Traducido por Agustín Neira. Madrid: Trotta.

Ring, Jim (2000). How the English made the Alps. Londres: Murray.

Robertson, David (1977). «Mid-Victorians amongst the Alps». En: Knoepflmacher, U.C. y Tennyson, G.B. (eds.). Nature and the Victorian Imagination. Berkeley: University of California Press, 113-136.

Saule-Sorbé, Hélène (1993). Pyrénées: Voyage par les images. Serres-Castet: Faucompret.

- (2010). "Arte y geografía en las representaciones modernas del paisaje: El caso de los Pirineos». Estudios Geográficos [en línea], 71 (269), 475-504. <http://dx.doi.org/10.3989/estgeogr.201016>

Schama, Simon (1996). Landscape and Memory. Nueva York: Vintage.

Siganos, André y Vierne, Simone (eds.) (2000). Montagnes imaginées, montagnes représentées: Nouveaux discours sur la montagne de l'Europe au Japon. Grenoble: Ellug.

Thomas, Martin (2004). The Artificial Horizon: Imagining the Blue Mountains. Melbourne: Melbourne University Press.

Thompson, Simon (2011). Unjustifiable Risk?: The Story of British Climbing. Milnthorpe, Cumbria (UK): Cicerone.

Titos Martínez, Manuel (ed.) (1992). Sierra Nevada en los viajeros románticos. Granada: Caja General de Ahorros de Granada.

- (1997). Sierra Nevada: Una gran historia. Vol. 1. Granada: Universidad de Granada.

- (ed.) (2002). Textos históricos sobre Sierra Nevada: Historia viva. Madrid: Organismo Autónomo Parques Nacionales.

- (2004). Esquiar en Granada: Historia del esqui en Sierra Nevada, 90 años después. Granada: Ayuntamiento de Granada.

- (2014). Historia del esqui en Sierra Nevada: 1914-2014, 100 años de esfuerzo y pasión. Granada: Cetursa.

Titos Martínez, Manuel y Piñar Samos, Javier (eds.) (2009). Luces de Sulayr: Cinco siglos en la imagen de Sierra Nevada [cat. exp.]. Granada: Fundación Caja Granada.

Tort i Donada, Joan (2007). «Cuatro escritores (Verdaguer, Ruyra, Pla y Manent) en la conformación del "canon paisajístico" catalán». Ería, 73, 351-372.

VEGA, Jesusa (2004). «Viajar a España en la primera mitad del siglo xix: Una aventura lejos de la civilización». Dialectología y Tradiciones Populares, LIX (2), 93-125.

Walter, François (1989). "Attitudes towards the environment in Switzerland, 18801914». Journal of Historical Geography [en línea], 15 (3), 287-299. <http://dx.doi.org/10.1016/S0305-7488(89)80118-5>

- (2004). Les figures paysagères de la nation: Territoire et paysage en Europe (16e-20e siècle). París: École des Hautes Études de Sciencies Sociales. 
- (2005). «La montagne alpine: Un dispositif esthétique et idéologique à l'échelle de l'Europe». Revue d'histoire moderne et contemporaine, 52 (2), 64-87.

Whelan, Yvonne y Moore, Niamh (eds.) (2006). Heritage, Memory, and the Politics of Identity: New Perspectives on the Cultural Landscape. Aldershot: Ashgate.

Willкomm, Moritz (1993). Las sierras de Granada (1882). Traducido por Rafael Zambrana Kuhn. Granada: Caja General de Ahorros y Monte de Piedad de Granada. 